\title{
Enhancement by tetragastrin of experimental induction of gastric epithelium in the duodenum
}

\author{
M TATSUTA, H IISHI, H YAMAMURA, R YAMAMOTO, \\ AND H TANIGUCHI \\ From the Departments of Gastrointestinal Oncology and of Pathology, The Center for Adult Diseases, Osaka, \\ Japan
}

SUMmary The effects of tetragastrin and truncal vagotomy on the incidence of gastric type epithelium in the duodenum by intraduodenal instillation of $5 \% \mathrm{NaOH}$ solution were investigated in Wistar rats. Prolonged administration of $1 \mathrm{mg}$ tetragastrin/kg body weight in depot form starting one week after $\mathrm{NaOH}$ treatment resulted in a significant increase in gastric acid secretion and the incidence and number of villi with gastric epithelium in the duodenum in experimental week 10. Villi with gastric epithelium were found in five (23\%) of 22 rats in control group, whereas abnormal villi were found in $13(59 \%)$ of 22 rats in the tetragastrin treated group $(p<0 \cdot 05)$. The average number of villi with gastric epithelium rose from $0.6(0.4)$ per 100 villi in control rats to $2.4(0.6)$ per 100 villi in tetragastrin treated rats $(p<0.01)$. On histological examination, gastric type epithelium was most often found on stunted or flattened villi, and was always within the boundaries of the area of Brunner's glands. These mucosal changes reverted toward normal with time. In week 35, the incidence of gastric epithelium was significantly less than at week $10(p<0 \cdot 05)$. In contrast, no villi with gastric epithelium were found in vagotomised rats in week $10(p<0 \cdot 05)$. Vagotomy also caused a significant decrease in gastric acid secretion. These results show that exposure of the duodenal mucosa to high levels of gastric acid enhance the induction of gastric epithelium in the duodenum.

In 1964 James described the partial replacement of the normal epithelial cells of the human duodenal mucosa by epithelial calls containing mucus.' Since then, gastric type epithelium has frequently been seen in patients with duodenal ulcer ${ }^{2}$ and duodenitis. ${ }^{3}$ These mucosal changes are thought to constitute a protective mechanism, involved in some way with ulcer healing. ${ }^{4}$ The histogenesis of these changes, however, is still under discussion.

In 1964, Rhodes reported that the administration of histamine induced gastric type epithelium in the duodenum of the cat. ${ }^{5}$ We recently reported that prolonged administration of tetragastrin decreased the incidence and number of intestinal metaplasias induced by intragastric instillation of $\mathrm{NaOH}$ solution in rats. ${ }^{6}$ In the present work, we applied this method to the duodenum, and examined the effect of tetra-

Address for correspondence: Dr Masaharu Tatsuta, Department of Gastrointestinal Oncology. The Center for Adult Diseases. Osaka 3-3. Nakamichi 1-chome. Higashinari-ku. Osaka 537, Japan.

Accepted for publication 25 August 1988. gastrin on the production of gastric epithelium in the duodenum.

Methods

ANIMA.LS

We used 155 six week old male inbred Wistar rats weighing $100-120 \mathrm{~g}$. The rats were randomly divided into four groups, and treated as follows.

Groups 2, 3, and 4 (40 rats each) received intragastric instillation of $\mathrm{NaOH}$ solution by Oohara's method' as previously modified by us. ${ }^{6}$ Briefly, the rats were starved for 48 hours, then the abdomen was opened and the stomach raised. The oesophagus and duodenum were clamped from the outside with arterial clamps $2 \mathrm{~cm}$ from the gastric pylorus, and $3 \cdot 0$ $\mathrm{ml}$ of $5 \% \mathrm{NaOH}$ solution was injected into the stomach with a fine needle (outside diameter, 0.5 $\mathrm{mm}$ ) inserted through the forestomach. One minute later, the fluid contents were aspirated as completely as possible through an 18 gauge needle of $1.2 \mathrm{~mm}$ outside diameter through the forestomach. 
After the $\mathrm{NaOH}$ instillation, the group 4 rats were subjected to truncal vagotomy as described by Lambert. ${ }^{8}$ The vagal nerve fibres and peritoneum were stripped away from the lower oesophagus immediately above its junction with the stomach. Pyloroplasty was not carried out.

Groups 2 and 3 underwent a sham operation, in which the vagus was exposed but left intact. The group 2 animals received $2 \mathrm{ml} / \mathrm{kg}$ body weight of olive oil alone subcutaneously on alternate days and group 3 received $1 \mathrm{mg}$ tetragastrin $/ \mathrm{kg}$ body weight (Nissui Pharmaceutical Co, Tokyo, Japan) in $2 \mathrm{ml}$ olive oil subcutaneously on alternate days. For both groups, the injections were given between 2 and 3 pm every other day throughout the experiment, using a different injection site each time.

As a control, group 1 ( 35 rats) was subjected to the same operation as groups 2,3 , and 4 , but received $3 \mathrm{ml} 0.9 \% \mathrm{NaCl}$ solution instead of $\mathrm{NaOH}$ solution intragastrically, and then olive oil as in group 2.

Treated rats were killed at weeks 10 and 35 . The stomach and duodenum were opened, pinned on a cork mat, and then fixed with $10 \%$ neutralised formalin solution. After fixation, three longitudinal strips $3 \mathrm{~mm}$ wide and $2 \mathrm{~cm}$ long were cut from the duodenum, including the gastroduodenal junction. The specimens were kept flat and embedded in paraffin. Two sections $5 \mu \mathrm{m}$ thick were obtained from each embedded specimen, and were stained with haematoxylin and eosin and with alcian blueperiodic acid-Schiff (PAS). On six slides from each rat, the number of villi with gastric epithelium were counted over the whole length of the specimen, with no knowledge of the group from which they came. Particular attention was paid to the nature of the surface epithelium and to the presence of mucus containing cells resembling gastric cells, but gastric type epithelium within five villi of the gastroduodenal junction was not scored. The number of villi with gastric type epithelium was expressed as the number per 100 villi examined.

Duodenal $\mathrm{pH}$ and gastric secretion were determined at weeks 10 and 35 . For the measurement of duodenal mucosal $\mathrm{pH}$, the rats were first starved for 24 hours, and then received the following sc injections: groups 1 and 2, olive oil, $2 \mathrm{ml} / \mathrm{kg}$ body weight, and group 3 , tetragastrin, $1 \mathrm{mg} / \mathrm{kg}$ body weight. Group 4 rats received no injection. One hour later, the animals were killed and the duodenum was opened. The $\mathrm{pH}$ of the duodenal mucosa was measured with a fine $\mathrm{pH}$ electrode.

Gastric secretion was measured in different rats than those used for the $\mathrm{pH}$ measurement. Gastric secretion was collected for two hours by the method of Shay et al..$^{9}$ After the pylorus ligation, the rats received the following sc injections: groups. 1 and 2 ,

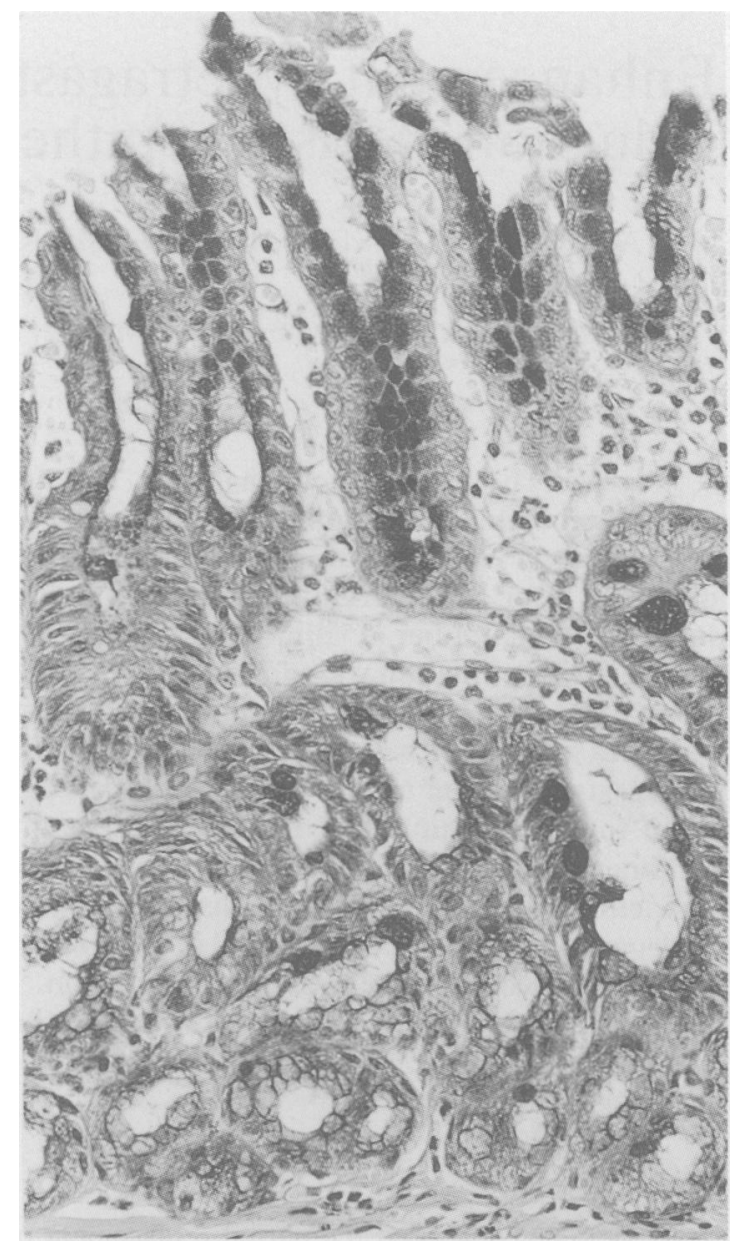

Figure Photomicrograph of stunted villi in the duodenum with gastric epithelium (alcian blue and PAS).

olive oil, $2 \mathrm{ml} / \mathrm{kg}$ body weight, and group 3 , tetragastrin, $1 \mathrm{mg} / \mathrm{kg}$ body weight. Group 4 rats received no injection. Then the acid output was calculated.

Data are given as means (SE). Statistical analyses were done with the $\chi^{2}$ test ${ }^{11}$ or one-way analysis of variance with Dunn's multiple comparison."12 'Significant' indicates a calculated $p$ value of less than $0 \cdot 05$.

\section{Results}

INCIDENCE AND NUMBER OF GASTRIC

EPITHELIUM AT WEEK 10

Three, five, five, and two rats from groups 1 to 4 , respectively, died within 10 days after the laparotomy, and were excluded from effective numbers. 
Table 1 Incidence, number and form of villi with gastric epithelium in the duodenum in week 10

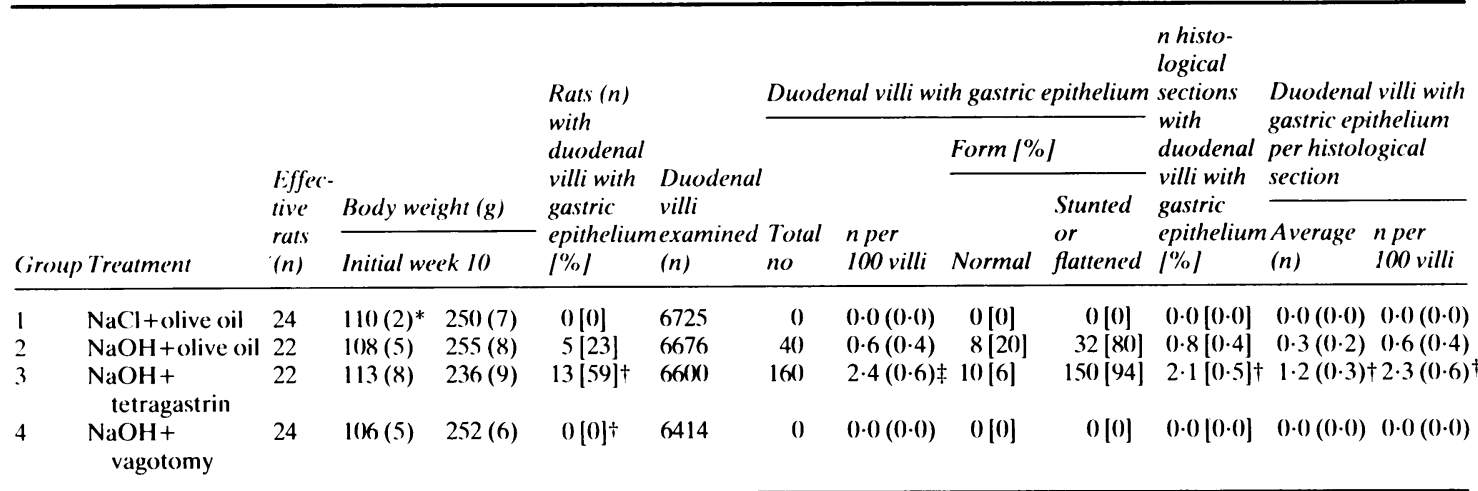

*Means (SE). Significance of differences from values in group $2: \dagger p<0 \cdot(05 ; \neq p<0 \cdot(01$.

Histologically, no rats had duodenal ulcerations, but almost all the $\mathrm{NaOH}$-treated rats had many superficial duodenal erosions. Gastric type epithelium was easily distinguished with PAS staining. As shown in the Figure, gastric type epithelium contained PAS-positive and alcian blue negative mucin. The cells composing it had mucus droplets near the surface, and had no brush border.

The incidence, number, and form of duodenal villi with gastric epithelium in $\mathrm{NaOH}$-treated and control rats at week 10 are summarised in Table 1 . In group 3 $(\mathrm{NaOH}$ and tetragastrin), the incidence and number of villi with gastric epithelium were significantly greater than in group $2(\mathrm{NaOH}$ and olive oil). In contrast, the incidence was significantly lower in group $4(\mathrm{NaOH}$ and vagotomy) than in group 2 . No villi with gastric epithelium were found in group 1 ( $\mathrm{NaCl}$ and olive oil).

The gastric type epithelium was most often seen on stunted or flattened villi, but occasionally on normal villi. In group 2, gastric epithelium was found on normal villi more frequently in group 2 than in group 3 , but the difference was not significant. All gastric type epithelium was found within the boundaries of the area of Brunner's glands, and never on mucosa that did not overlie Brunner's glands. All gastric epithelium was observed to be in the superficial layer of the duodenal mucosa. No rats had gastric epithelium extending from the surface of the mucosa to the muscularis mucosae and continuing to Brunner's glands.

INCIDENCE AND NUMBER OF GASTRIC

E.PITHEIIUM AT WEEK 35

Onc rat in group 2 and three rats in group 4 died between weeks 11 and 34 , and were excluded from the effective numbers. In groups 1, 2, 3, and 4, respectively, $8,12,13$, and 11 rats were examined at week 35 .

At week 35, no gastric epithelium was found in groups $1(\mathrm{NaCl}$ and olive oil), $2(\mathrm{NaOH}$ and olive oil), or $4(\mathrm{NaOH}$ and vagotomy). In group $3(\mathrm{NaOH}$ and tetragastrin), the incidence of gastric epithelium was significantly $(\mathrm{p}<0.05)$ less than at week 10 : a total of the 20 villi with gastric epithelium were found, in only two (15\%) of the 13 rats. All gastric type epithelium was found on stunted or flattened villi, and within the boundaries of the area of Brunner's glands.

Table 2 Duodenal mucosal pH and gastric acid secretion in weeks 10 and 35

\begin{tabular}{|c|c|c|c|c|}
\hline \multicolumn{3}{|c|}{ Week Group Treatment } & \multirow{2}{*}{$\begin{array}{l}\begin{array}{l}\text { Duodenal } \\
p H^{+}\end{array} \\
3 \cdot 1(0 \cdot 3)^{*}[10]\end{array}$} & \multirow{2}{*}{$\begin{array}{l}\begin{array}{l}\text { Gastric acid secretion } \\
(\mathrm{mmol} / \mathrm{h})^{\dagger}\end{array} \\
0 \cdot 1062(0 \cdot 0080)[6]\end{array}$} \\
\hline 10 & 1 & $\mathrm{NaCl}+$ olive oil & & \\
\hline & 2 & $\mathrm{NaOH}+$ olive oil & $4 \cdot 6(0 \cdot 2)[10]$ 扠 & $0.0318(0.0062)[6] \$ \rrbracket$ \\
\hline & 3 & $\begin{array}{l}\mathrm{HaOH}+ \\
\text { tetragastrin }\end{array}$ & $3 \cdot 2(0 \cdot 2)[10]$ & $0 \cdot 1279(0 \cdot 0077)[5]$ \\
\hline & 4 & $\begin{array}{l}\mathrm{NaOH}+ \\
\text { vagotomy }\end{array}$ & $6 \cdot 4(0 \cdot 6)[10]$ 扠 & $0.0014(0.0007)[6] \pm \|$ \\
\hline \multirow[t]{4}{*}{35} & 1 & $\mathrm{NaCl}+$ olive oil & $3 \cdot 0(0 \cdot 4)[4]$ & $0 \cdot 1064(0 \cdot 0070)[4]$ \\
\hline & 2 & $\mathrm{NaOH}+$ olive oil & $5 \cdot 2(0 \cdot 3)[5] \S \rrbracket$ & $0.0389(0.0051)[6] \pm \|$ \\
\hline & 3 & $\begin{array}{l}\mathrm{NaOH}+ \\
\text { tetragastrin }\end{array}$ & $2 \cdot 7(0 \cdot 2)[5]$ & $0 \cdot 1288(0 \cdot 0121)[5]$ \\
\hline & 4 & $\begin{array}{l}\mathrm{NaOH}+ \\
\text { vagotomy }\end{array}$ & $6 \cdot 4(0 \cdot 3)[5] \div$ & $0.0008(0.0006)[6]+4$ \\
\hline
\end{tabular}

*Means (SE).

†Numbers in square brackets are numbers of rats examined.

Duodenal $\mathrm{pH}$ and gastric acid secretion were measured in different rats.

Significance of differences from values in group $1: \ddagger \mathrm{p}<0 \cdot 001$; $\$ \mathrm{p}<0 \cdot 05$.

Significance of differences from values in group $3: \| \mathrm{p}<0 \cdot(001$ : $9 \mathrm{p}<0.05$ 
DUODENAL PH AND GASTRIC ACID SECRETION Table 2 shows that at both weeks 10 and $35, \mathrm{NaOH}$ treatment resulted in a significant increase in duodenal $\mathrm{pH}$ and decrease in gastric acid secretion as compared with control group $1(\mathrm{NaCl}$ and olive oil $)$. Administration of tetragastrin in group 3 caused a significant decrease in duodenal $\mathrm{pH}$ and a significant increase in gastric acid secretion as compared with group 2 . In contrast, the vagotomy performed in group 4 resulted in a significant rise in duodenal $\mathrm{pH}$ and a significant decrease in gastric acid secretion.

\section{Discussion}

Gastric type epithelium is often found on the duodenal villi of patients with duodenal ulcers. ${ }^{24}$ Florey and Harding showed that artificial defects of the duodenal mucosa in cats healed by an epithelium of superficial gastric type..$^{13}$ Later, they found that many contiguous villi in experimental pig duodenal loop fistulae were covered with mucus containing columnar cells similar to those lining the stomach. ${ }^{14}$ Morrissey et al found that in duodenal ulcerations, the alcian-blue-staining acid mucosubstances in goblet cells are reduced, and PAS-staining neutral mucosubstances appear in the cells of the surface epithelium. ${ }^{4}$ Spicer et al considered gastric and duodenal mucin to be two distinct types of mucoproteins. ${ }^{15}$ Gastric mucin secreted by the mucous neck cells produces a PAS-positive, neutral mucosubstance. This secretion forms a continuous mucus film over the gastric mucosa, protecting the mucosa from the highly acidic gastric secretions. Duodenal mucin is a sulphated acid mucosubstance, produced by the goblet cells and released over a relatively short period of time. Therefore, we suggest that the appearance of the mucous neck cell type epithelium in the duodenum is a protective response to the presence of ulceration. ${ }^{124516}$ These cells isolate the zone of erosion from the healthy mucosa and, by continuously secreting gastric mucin, protect the ulcer crater from further damage, thus promoting healing.

Two hypotheses have been proposed to explain the histogenesis of gastric type mucosa in the duodenum. One is that gastric epithelium develops from cells lining the ducts of Brunner's glands. ${ }^{516}$ This hypothesis was based on the apparent continuity of Brunner's glands with the surface epithelium showing mucous changes. The other hypothesis postulates a derivation from stem cells in the crypts of Lieberkühn surrounding an ulcer. ${ }^{2}$ This idea was based on a sequence of ultrastructural changes found in villar epithelial cells, from a gastric secretory to a duodenal absorptive cell type. In the present work, we found no continuity between the duct of
Brunner's glands and crypt with mucous changes, although gastric type epithelium was found only within the boundaries of the area of Brunner's glands.

James reported that gastric type epithelium tended to develop in the duodenum when duodenal acidity is high, and suggested that gastric acid secretion per se may be responsible for the development of gastric type epithelium.' Rhodes reported that administration of histamine suspended in beeswax increased gastric acid secretion and induced these changes in the duodenum of cats. As previously reported, ${ }^{2}=1516$ gastric type epithelium is considered to be a reparative epithelium in the duodenum. Therefore, in the present work, we administered tetragastrin as a suspension in olive oil to rats with duodenal erosions induced by intragastric instillation of $5 \% \mathrm{NaOH}$ solution, to enhance the development of gastric type epithelium in the duodenum. We found that gastric epithelium was significantly more abundant in rats treated with tetragastrin. We also found that vagotomy after $\mathrm{NaOH}$ treatment significantly decrease the incidence of gastric-type epithelium, although a better control group for reducing acid secretion might have been animals treated with acid inhibiting agents. Our findings also indicate that exposure of the duodenal mucosa to increased acid enhanced the induction of gastric type epithelium in the duodenum.

\section{References}

1 James AH. Gastric epithelium in the duodenum. Gut 1964; 5: 285-94.

2 Gregory MA, Moshal MG, Spitaels JM. Changes in the morphology of villar epithelium cells adjacent to duodenal ulcers during the process of healing. Scand $J$ Gastroenterol 1982; 17: 441-8.

3 Shousha S, Spiller RC, Parkins RA. The endoscopically abnormal duodenum in patients with dyspepsia: biopsy findings in 60 cases. Histopathology 1983; 7: 23-34.

4 Morrissey SM, Ward PM, Jayaraj AP, Tovey FI, Clark CG. Histochemical changes in mucus in duodenal ulceration. Gut 1983; 24: 909-13.

5 Rhodes J. Experimental production of gastric epithelium in the duodenum. Gut 1964; 5: 454-8.

6 Tatsuta M, Yamamura H, Baba M, Yamamoto R, lishi $H$, Taniguchi $H$. Inhibitory effect of prolonged administration of tetragastrin on experimentally induced intestinal metaplasia in Wistar rats. Cancer. 1988; 61: 2051-6.

7 Oohara T, Hirukawa K. New method of experimental production of regenerative epithelium of the stomach in the rat - induction of experimental intestinal metaplasia due to regenerative process. Igaku-no-ayumi 1980; 113: 824-6.

8 Lambert R. Surgery of the digestive system in the rat. Springfield, Il: Thomas, 1965: 477-81.

9 Shay H, Sun DCH, Gruenstein M. A quantitative 
method for measuring spontaneous gastric secretion in the rat. Gastroenterology 1954; 26: 906-13.

10 Siegel S. Nonparametric statistics for behavioral sciences. New York: McGraw-Hill, 1956.

11 Lehmann EL. Nonparametrics. San Francisco: HoldenDay, 1975.

12 Miller RG Jr. Simultaneous statistical inference. New York: McGraw-Hill, 1966.

13 Florey HW. Harding HE. The healing of artificial defects of the duodenal mucosa. J Pathol Bacteriol 1935; 40: $211-8$.
14 Florey HW, Jennings MA, Jennings DA, O`Connor $\mathrm{RC}$. The reactions of the intestine of the pig to gastric juice. J Pathol Bacteriol 1939; 49: 105-23.

15 Spicer SS, Leppi TJ, Stoward PJ. Suggestions for a histochemical terminology of carbohydrate-rich tissue components. J Histochem Cytochem 1965; 13: 599-603.

16 Patrick WJA, Denham D, Forrest APM. Mucous changes in the human duodenum: A light and electron microscopic study and correlation with disease and gastric acid secretion. Gut 1974; 15: 767-76. 